\title{
The Mediating Role of Customer Satisfaction among SERVQ and Loyalty in the Banking Sector
}

\author{
Walid Droubi ${ }^{1} \&$ Nizar Raissi ${ }^{1}$ \\ ${ }^{1}$ College of Islamic Economics and Finance, Umm Al Qura University, Makkah, Saudi Arabia \\ Correspondence: Nizar Raissi, College of Islamic Economics and Finance, Umm Al Qura University, Makkah, Saudi \\ Arabia. Tel: 966-53-417-3088.
}

Received: October 20, 2016

Accepted: November 11, 2016

Online Published: November 12, 2016

doi:10.5430/ijba.v7n6p72

URL: http://dx.doi.org/10.5430/ijba.v7n6p72

\begin{abstract}
This study aims to measure the effectiveness of service quality in Islamic banks compared to conventional banks with the objective of improving the performance of those banks, taking into consideration the customer's point of view in this regard, and hoping to offer an effective contribution to creating an Islamic alternative to conventional banks. The researchers have adopted in their perception of this study on the KSA's market as a sample for the analysis of the status of Islamic banks in terms of the services provided to customers. Thus, the research is based on investigation and we used a sample of 1050 clients from Saudi Bank sector. Therefore, the analysis of our sample used exploratory factor analysis (EFA) and confirmatory factor analysis (CFA) presented a multitude of structural relations path that gave rise to different results. In case of $\mathrm{CB}$, the results shown that exist a direct effect between customer satisfaction, empathy, assurance and tangibles. The loyalty has an indirect effect within empathy, assurance, tangibles and a direct effect within customer satisfaction variable. However, in case of IB, the results indicated that exist a direct effect between customer satisfaction, responsiveness and reliability. The loyalty has an indirect effect within responsiveness, reliability, and direct effect within customer satisfaction. The role of customer satisfaction as a mediator between service quality and loyalty is major in both cases. Findings revealed that each type of banks presented its specificity in service quality.
\end{abstract}

Keywords: effectiveness, reliability, satisfaction, responsiveness, loyalty, empathy, assurance and tangibles

\section{Introduction}

Nowadays, quality has become imperative to follow for companies, especially for banks. Indeed, customers increasingly solicited, changing and demanding to show, furthermore, eager to be involved in the development of the service. And they are constantly demanding better quality of products and services flawless. In fact, the idea of quality is not only based on concepts from the sciences of matter (strength, durability and power), Dietrich, A., and Wanzenried, G. (2011); Sufian, F. and Abdul Majid, M.Z. (2007). It also seeks the service provided by the Product and integrates notions that belong to the register of cognitive science (comfort, aesthetics ...). We will situate not only from the product side and its features, but also from the client that also seeks the quality of service that follows (Raissi, N., \& Chaher, M., 2014). Therefore, the relationship with the client becomes increasingly central. The main asset, the one that makes the difference, is the adaptation of service to customer needs, with quality production or realization. Adding to the competitive price, these "quality" assets allow banks to take the markets by improving their services (security, hosting, availability, lead times and customer focus) and innovative nature of their products (Islam, S., and Borak Ali, Md., (2011); Sufian, F., and Majid, M.Z.A., 2011). Although as a tool for the strategy of banks, quality of service is increasingly focused on quality assurance and ISO certification. Indeed, the margins for maneuver are located especially on the side of the quality of service returned to the customer. This approach is favored by the advantage of partnership relations between buyers and sellers, since the quality approach validates internal procedures of a bank and the quality system implemented to ensure the commitment of the service result (Idris, A.R, et al., 2011). The researchers concentrated in the first section of this article on the effect of quality service rendered in Islamic versus Conventional banks (IB v CB), which then led us to model the relationship between the quality of services and customer satisfaction as a new proposed approach to bank management in the second section. Likewise, we presented for a hypothetical-deductive approach both processes; the first at the level of the specific banking services and the second in terms of their quality. This idea is further developed in practice for a 
complex service provided by Islamic and conventional banks through a sample of 1050 clients in the Saudi banking sector.

\section{Literature Review and Research Problem Background}

\subsection{Purpose of the Literature Review}

Many studies have been made on comparison between Islamic and Conventional banks which has become a very important element in international financial markets, Kamaruddin, B. H., and al., (2008); Karim, M., and Chan, S.G. (2007); Masood,O. and Muhammad, A. (2012); Olson, D., and Zoubi, T.A. (2011); Viverita, Brown, K., and Skully, M., (2007). We chose to focus in this literature review on the effects of quality services on customer satisfaction and loyalty, although the latter concept is difficult to define since there various visions and aspects of customer satisfaction. Four keys customer satisfaction dimensions distinguished this research; Religious beliefs, Behavior of employees, Basic facilities and Reputation, which currently seem representative of the main banks issues. Also, the service quality determinants are defined by five concepts: tangibles, responsiveness, empathy, assurance and reliability.

\subsection{The Specificity of Islamic Banks}

The growing risks of Islamic banks resulting from the failure attention provided to customers services. This problem was pointed out by the authors Abedniya, A., \& Zaeim, M.N., (2011), "with the recent appear of Islamic banking, it can be said that there are severe operational risk in these institutions. Operational risk arises here when there are not available for Islamic banks qualified and trained human resources that are adequately able to carry out operations and services of Islamic Finance". Furthermore, the reputation plays an important role with clients and that reputational risk resulting from the presence of a negative reputation among customers for the bank or the service provided to them, Ponce, T. A., (2012). Abedniya, A., \& Zaeim, M.N., (2011), has written about this by saying: "may lead negative reputation to the loss of funding sources or could lead customers to convert to banks compete, and this impression is created as a result of the actions carried out by the manager or the bank staff or as a result of lack of customers quality service and the desired speed ". Abedniya, A., \& Zaeim, M.N., (2011) pointed out, "That may occurred problem of confidence risk as a result of violating contracts by Islamic banking between them and their clients". Nazal, A.I., (2015) argued that the evaluation of performance of service department in the Islamic banking has a great importance, "To succeed the assessment operation of the customer service it is required to follow-up to the complaints and to solve them, because the customer is acting positively only if he or she feels that he or she is respected". Additionally, Nazal, A.I., (2015) pointed out, "that must be exist many skills and knowledge that should be available in Islamic banking staff but they noted that there is a need to provide two conditions to staff of Islamic banks: The first condition is to know the legitimacy of controls associated with the provision of services and the extent of their differences depending on the services provided and the second condition that he or she has the ability and technical competence that provides speed and accuracy service as desired by the customer".

\section{Theoretical Framework and Research Hypotheses}

\subsection{Banking Service Determinants}

The authors Schaupp, L., and Bélanger, F., (2005) argued, "which has traditionally been a high contact service, the lack of direct human interaction in internet banking entails the need to examine the role of technology, shopping, and product factors to construct e-CS (e-Customer Satisfaction)". Other researchers like Methlie, L., Nysveen, H., (1999) said that, "Banks must have the knowledge on how to get their customer satisfied, especially in relation to the e-SQ (e-Service Quality), and in internet banking, it shall be prioritized". Ravichandran and al., (2010) idicated that, "Services offered by banks are similar so that it becomes difficult for customers to distinguish one form". Moreover, Blanchard and Galloway, (1994) said: "it is important that banks strive to improve their service quality levels in order to gain competitive advantage. This, coupled with customer sovereignty, given by the large number of banks, suggests that customer needs cannot be neglected". Tsoukatos and Mastrojianni, (2010) said that: "Banks need to anticipate or identify those factors which may affect the quality of their services as a result of the changes in the environment in which they operate". According to Parasuraman and al. $(1985 ; 1988 ; 1994)$, "the perceived service quality is defined as a: "global judgment, or attitude, relating to the superiority of the service". The authors Yavas et al., (2004); Harrison-Walker, L. Jean., (2001) argued that, "the Service quality influences strongly customers' perceived value, satisfaction, re-visit as well as word-of-mouth intentions". Cronin and Taylor (1992) indicated that, "service quality could be best measured based on three factors namely, expectations, performance and importance of several service characteristics such as equipment and service environment, employees appearance and performance and service delivery in the context of banking sector". 


\subsection{Development of Conceptual Model and Hypotheses}

The research model describes the relationship between each construct and its items and constructs between them. The variables are divided into three types "dependent variable", "independent variables" and "mediator variable". The dependent variable in this model represents the effect of variables correlation and is noted "Loyalty". The "independent variables" represent causes and are distinguished by the "five dimensions of service quality construct". The "mediator variable" is a third explanatory variable and it served to identify the nature of relationship between the independent and dependent variables, in this research was identified as "customer satisfaction".

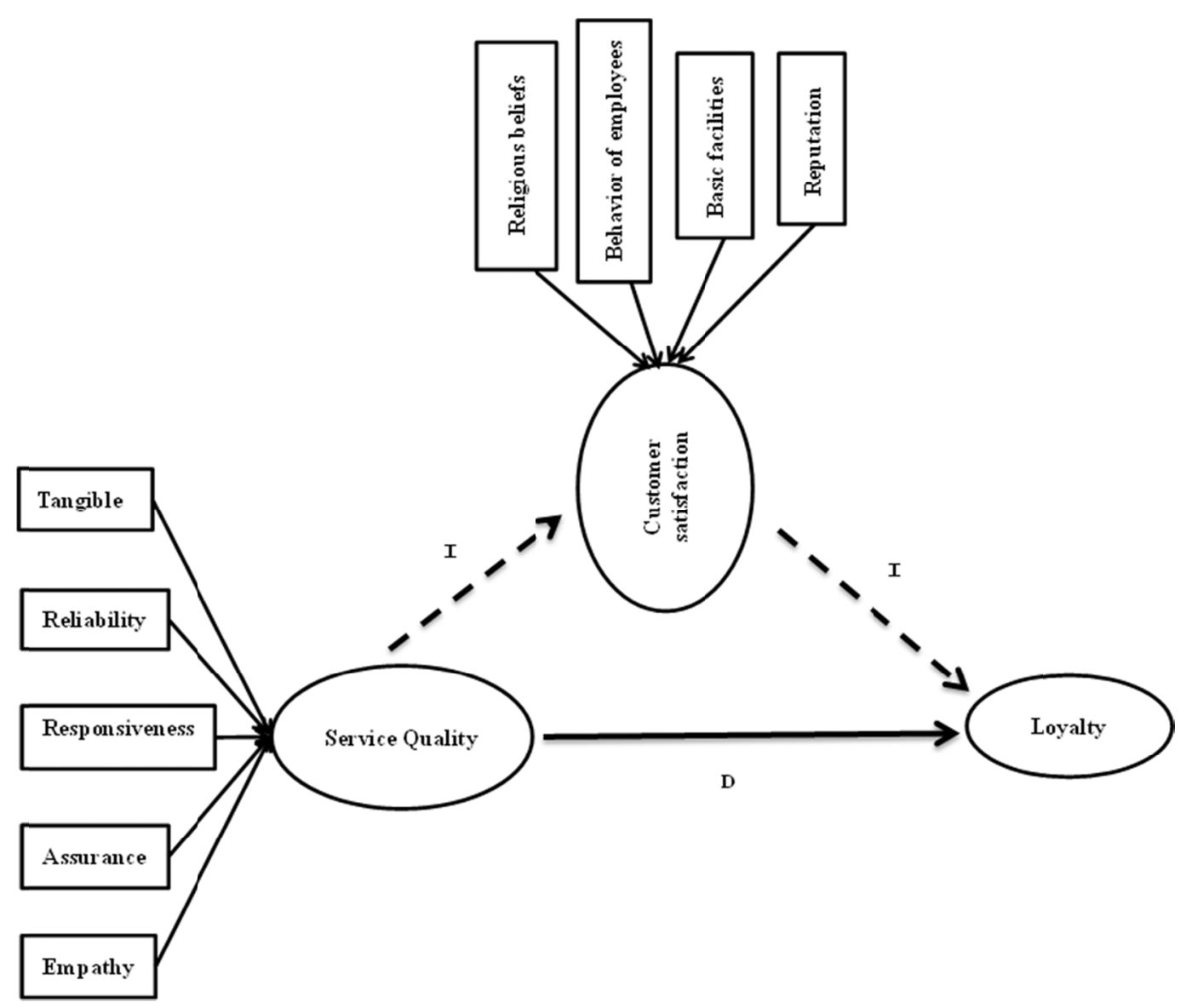

Figure 1. The relationship between determinants of banking services, customer satisfaction and Loyalty (cases of IB versus $\mathrm{CB}$ )

Notes: D - direct; I - indirect

Hypothesis 1: The Islamic banks provide services quality to customers better than conventional banks. The researchers tried through this study to prove that banks services offered by Islamic system are more efficient than conventional system. This hypothesis was tested with five criteria which represented a construct Service quality. Then, the five service quality determinants are defined as tangibles, reliability, responsiveness, assurance and empathy, Abedniya, A., \& Zaeim, M.N., (2011); Islam. S., and Borak Ali, Md., (2011); Blanchard and Galloway, (1994).

Hypothesis 2: The loyalty to the service quality of Islamic banks has greater efficiency than conventional counterparts. To test this hypothesis, the researchers suggested that loyalty was the dependent variable and service quality and customer satisfaction were the independent variables. The construct Loyalty is influenced by five dimensions of service quality and four criteria lead to customer satisfaction. In this first case, the researchers tested the Loyalty construct and to clarify the nature of relationship between banks and client in two systems, the first system for Islamic banks and the second about conventional banks. Then, the researchers confirmed that the loyalty 
of clients affiliated to Islamic banks is greater than who affiliated to conventional banks, Ravichandran and al., (2010); Abedniya, A., \& Zaeim, M.N., (2011); Ehigie, (2006); Zeitun, R. (2012).

Hypothesis 3: Religious beliefs play a major role on customer satisfaction in Islamic banks than conventional banks. The choice of religious beliefs criteria which define customer satisfaction were proved by the nature of Islamic banks. This system based on Chariaa's requirements and the confidence gives to Islamic banks by many financial institutions in the world (World Bank, IFM, IDB,...), all of this encouraged researchers to study the importance of religious beliefs and its impact on customer satisfaction, Jham \& Khan (2008); Nazal, A.I., (2015); Methlie, L., and Nysveen, H., (1999).

Hypothesis 4: The behavior of employees has a positive and greater impact on customer satisfaction in Islamic banks than conventional banks. The role of employees and their behaviors include employees' knowledge, courtesy and ability to convey trust and confidence to the clients and stakeholders (Islam. S., and Borak Ali, Md., 2011). This variable defines the customer satisfaction and after test it in two cases (Islamic and conventional banks). The researchers will be able on the one hand to explain the relationship between behavior employees and customer satisfaction, and on the other hand to confirm its greater impact for Islamic banks than conventional banks.

Hypothesis 5: The basic facilities have a positive and greater impact on customer satisfaction in Islamic banks than conventional banks. The basic facilities variable comprises interest given on savings, commission taken for services, interest charged for loans, Issuance of credit and debit cards, Electronic fund transfers, etc. The varieties of facilities package service enhance customer satisfaction. Therefore, it exists a need to test the relationship between basic facilities variable and customer satisfaction in two cases, Islamic and conventional banks, Lee et al. (2000).

Hypothesis 6: The reputation has a positive and greater impact on customer satisfaction in Islamic banks than in conventional banks. The reputation variable gives an idea about the strength of bank system and its quality service, and the ability of bank to satisfy clients. Therefore, a bank's clients have a tendency to be more loyal if they enjoy excellent reputation and relationship. The researchers in this type of study distinguish that reputed banks are able to provide high quality services. The reputation facilitates a stronger captivity and closer relationship with the bank, Islam. S., and Borak Ali, Md., (2011); Abedniya, A., \& Zaeim, M.N., (2011).

Hypothesis 7: There are positive and greater relationships between service quality and customer satisfaction regarding Islamic banks $\mathrm{v}$ conventional banks. The customer satisfaction is recognized as being highly associated with two dimensions, one is perceived quality and the second is perceived value. Specifically, there has been a convergence between the feeling of satisfaction and the service offered by bank, (Fornell et al, 1996; Ahmad and Hasan (2007), Jham \& Khan 2008 and Lee et al. 2000; Islam. S., and Borak Ali, Md., 2011). The customer satisfaction and service quality are the significant predictors of customer loyalty (Ehigie, 2006).

\section{Research Methodology}

\subsection{Background}

The purpose of this part is to describe the different steps and methodological precautions implemented in order to have relevant, reliable and valid statistical analysis which will verify (or possibly invalidate) the hypotheses of the research presented in the past section. At first "Questionnaire Design", the researchers justified the selection of items designed to measure the various built in assumptions involved in research. Depending on the nature of the constructs; (opinion, intention and/or managerial practice), also to justify the approach to the construction of measurement scales (monadic or comparative approach). In a second step "pre-tests", the researchers presented the terms of preliminary validation of the questionnaire answers received from clients of banks in Saudi Arabia. In this research, the objective of data collection is to present the procedures for administering the questionnaire to a wide number of people and justify external validity of study. Finally, for validation of variables, researchers presented the results on the reliability and validity of internal operational measures, and those relating to the criterion of independence of variables that must be checked later to conduct multiple regression analysis.

\subsection{Sample}

To determine the sample of study, we have used the database available at the Ministry of finance and the official website of central bank in Saudi Arabia (11 banks). Also, to provide some answers to research questions, we took the banking sector in Saudi Arabia (Islamic and conventional banks). The sample is represented by 1050 respondents from all banks customers' categories in Saudi Arabia. Note that in this level of empirical research, we have considered distribution criteria such as: working class and types of banks. 
Table 1. Working class

\begin{tabular}{llrrrr}
\hline & & Frequency & Percent & Valid Percent & Cumulative Percent \\
\hline \multirow{7}{*}{ Valid } & 631 & 60.1 & 60.1 & 60.1 \\
\cline { 2 - 6 } & Employee & 25 & 2.4 & 2.4 & 62.5 \\
\cline { 2 - 6 } & Other & 152 & 14.5 & 14.5 & 77.0 \\
\cline { 2 - 6 } & Professional & 242 & 23.0 & 23.0 & 100.0 \\
\cline { 2 - 6 } & Student & 1050 & 100.0 & 100.0 & \\
\cline { 2 - 6 } & Total & & & &
\end{tabular}

Table 1 about indicated that $60.1 \%$ of the sample were employees and $23 \%$ were students, these categories presented more than $83 \%$ of respondents. Table 2 shows that the sample is divided in two groups; the first group of respondents presented $51.8 \%$ of customers were from conventional banks and the second group presented $48.2 \%$ of customers were from Islamic banks.

Table 2. Banking system

\begin{tabular}{llrrrr}
\hline & & Frequency & Percent & Valid Percent & Cumulative Percent \\
\hline \multirow{3}{*}{ Valid } & Conventional Bank & 544 & 51.8 & 51.8 & 51.8 \\
\cline { 2 - 6 } & Islamic Bank & 506 & 48.2 & 48.2 & 100.0 \\
\cline { 2 - 6 } & Total & 1050 & 100.0 & 100.0 & \\
\hline
\end{tabular}

Once the research framework was defined, researchers focused on the different methods used for data collection. In fact, as a reminder the purpose of this empirical investigation were first, to check a number of proposals raised at the theoretical part. Second, to test a causal link, researchers showed that the degree of correlation existed between certain criteria; identified service quality, customer satisfaction and loyalty.

\subsection{Data Collection Method}

As part of empirical work, researchers conducted investigation by questionnaire. It contains two parts, the first part focused on the identification and the main features of the respondent, such as working class, gender, education level, etc., and the second part was devoted to test the strength and direction of possible link between service quality dimensions, customer satisfaction and loyalty. The survey was based on interview technique led to a pre-established questionnaire. Finally, to bring a measure to all of its criteria of the model developed, researchers chosen the "Likert scale". The choice can be justified, according to Evrard and al. (2009) by the fact that this scale is probably one of the best known in the opinion polls. It is supposed to be a good indicator for measuring the attitudes of clients. Researchers brought the interview to be placed on a continuum from a series of opinions on the same subject for which it should express more or less agree (disagree) by choosing between five possible answers (from Strongly disagree to Strongly agree). In a second step, researchers provided coding questions in the questionnaire to the address of data analysis software. After this consolidation, researchers conducted the recount, which allow us later to arrange data into tables within SPSS software. This software helps us to use the means of data analysis and to do exploratory factor analysis for validation of measures scales (Items).

\subsection{Analysis Procedures}

The analysis of data begins by the exploratory factor analysis. This statistical technique allows reducing data to a smaller set of summary variables. The measure thus established a correspondence between a theoretical (conceptual definition of the phenomenon) and an empirical level (definitions of criteria representing the phenomenon on which are the concrete operations of measurement). The operations on empirical measures in the context of the statistical analysis of results should be in correspondence with the relations that it is legitimate to establish between the concepts studied. Indeed, a measuring instrument must meet the following conditions: The choice of methods of analysis depends largely on the research objective pursued, Pett, M. A., and al., (2003). As this research used three methods of analysis: the first method was factor analysis to transform the variables involved in components (or factors) that summarize the best (the items which have the high consistency or reliability accepted), the second method was principal component analysis (PCA) for variables, (This technique is used when the researcher needs to reduce the number of factors and explain the maximum portion of variance in the initial variable), and the third method was structural equation modeling (SEM), designed to estimate and to represent causal relationships between constructs, and to validate the global model of research. The representations commonly used in the form of a set of 
linear equations, these were the simultaneous equations (in economics) or the analysis of networks, or path ways (in sociology), Shapiro, S. E., and al., (2002).

\section{Results and Data Analysis}

\subsection{Results}

Firstly, some descriptive statistics has been selected as frequency of customers' visits, the motivation to dealing with bank, and the transparency of banks about their service cost.

Table 3. The frequency of visits to bank branch every week

\begin{tabular}{llrrrr}
\hline & & Frequency & Percent & Valid Percent & Cumulative Percent \\
\hline Valid & 44 & 4.2 & 4.2 & 4.2 \\
\cline { 2 - 6 } & From 0 to 1 & 651 & 62.0 & 62.0 & 66.2 \\
\cline { 2 - 6 } & From 12 to 20 & 54 & 5.1 & 5.1 & 71.3 \\
\cline { 2 - 6 } & From 2 to 11 & 301 & 28.7 & 28.7 & 100.0 \\
\cline { 2 - 6 } & Total & 1050 & 100.0 & 100.0 & \\
\hline
\end{tabular}

The majority of customers (62\%) visited banks branch once per week. The second category visited banks from 2 to 11 times per week (28.7\%). It was clear that the customers haven't tradition to visit bank branch regularly. According to table 4 , there are $64.3 \%$ of customers, when they open a bank account, did not take into consideration that all transactions were done according to Islamic law. This result shows that the customers were not motivated by Islamic transactions or Islamic law, when opening account or taken banking service. Customers, when dealing with banks, they search for quality service and cost of transactions more than other thing. All details about this relationship, customer needs and banking service will be developed in modeling step later.

Table 4. When you open a bank account, you taken into consideration that all transactions according to Islamic law?

\begin{tabular}{llrrrr}
\hline \multirow{3}{*}{ Valid } & Frequency & Percent & Valid Percent & Cumulative Percent \\
\cline { 2 - 6 } & Neither agree nor disagree & 136 & 13.0 & 13.0 & 13.0 \\
\cline { 2 - 6 } & Somewhat agree & 157 & 15.0 & 15.0 & 27.9 \\
\cline { 2 - 6 } & Somewhat disagree & 246 & 23.4 & 23.4 & 51.3 \\
\cline { 2 - 6 } & Strongly agree & 82 & 7.8 & 7.8 & 59.1 \\
\cline { 2 - 6 } & Strongly disagree & 429 & 40.9 & 40.9 & 100.0 \\
\cline { 2 - 6 } & Total & 1050 & 100.0 & 100.0 & \\
\hline
\end{tabular}

The cost of service provided by banks and the transparency presented two main reasons which push or pull the desire or motivation of customers to choose between Islamic and conventional banks. The table 5 shows that $53 \%$ of banks customers confirm the presence of ambiguity and the complexity about the cost of service. The instructions about service prices presented in manual and guide are not clear and the customer finds a difficulty to understand the banks requirements and criteria for all service offers.

Table 5. The Bank shows the price of services provided to the customer with all the clarity and detail and there is no ambiguity for the client?

\begin{tabular}{llrrrr}
\hline \multirow{7}{*}{ Valid } & Frequency & Percent & Valid Percent & Cumulative Percent \\
\cline { 2 - 6 } & Neither agree nor disagree & 212 & 20.2 & 20.2 & 20.2 \\
\cline { 2 - 6 } & Somewhat disagree & 303 & 28.9 & 28.9 & 49.0 \\
\cline { 2 - 6 } & Somewhat agree & 215 & 20.5 & 20.5 & 69.5 \\
\cline { 2 - 6 } & Strongly agree & 67 & 6.4 & 6.4 & 75.9 \\
\cline { 2 - 6 } & Strongly disagree & 253 & 24.1 & 24.1 & 100.0 \\
\cline { 2 - 6 } & Total & 1050 & 100.0 & 100.0 & \\
\hline
\end{tabular}




\subsection{Data Analysis}

\subsubsection{Exploratory Factor Analysis}

The data analysis started by the validation of items (measurement scales), the first step is to use the reliability test with Cronbach's alpha (was considered acceptable at the threshold of 0.7) which helps to increase the consistency between items tested. And the second step to validate retained items with normality test through Skewness and Kurtosis coefficients whose the acceptance level (threshold) of all items should be between -3 and 3; Evrard and al. (2009). This phase of analysis presents the exploratory factor analysis.

\subsubsection{Reliability Test}

The reliability test was conducted to reduce the random part of measurement error. Its purpose is to find out if one measures the same thing several times with the same instrument to achieve results as close as possible.

\section{a- Reliability test of SERVQ variables}

The items selected from SERVQ variables and tested by Cronbach's alpha presented in table 6 shows that for the Tangibles variable the number of items retained after reducing the no consistency are 6 items for Alpha of Cronbach 0.783 . The test of Reliability variable obtained 4 items with $\alpha=0.623$. The test of Responsiveness variable gives 10 items with $\alpha=0.844$. The test of Assurance variable allows to have 7 items with $\alpha=0.762$. The last variable is Empathy which obtained 6 items after improvement items consistency with $\alpha=0.756$. Also, there were two latent variables which were deleted items, the Reliability and Assurance variables (Items deleted from model were: Rel1; Rel2; Ass4; Ass6; Ass8 and Ass9).

Table 6 . The reliability analyses of SERVQ variables

\begin{tabular}{cccc}
\hline Code & Variables of SERVQ & Number of items & Alpha of Cronbach \\
\hline Tan & Tangibles & $(6)$ & 0.783 \\
\hline Rel & Reliability & $(6) ;(5) ;(4)$ & $0.447 ; 0.526 ; 0.623$ \\
\hline Res & Responsiveness & $(10)$ & 0.844 \\
\hline \multirow{2}{*}{ Ass } & \multirow{2}{*}{ Assurance } & \multirow{2}{*}{$(11) ;(10) ;(9) ;(8) ;(7)$} & $0.654 ; 0.690 ; 0.724 ; 0.748 ;$ \\
& & $(6)$ & 0.762 \\
\hline Emp & Empathy & & 0.756 \\
\hline
\end{tabular}

\section{b- Reliability test of Customer satisfaction variables}

The same test is done for customer satisfaction variables which represented by 4 latent variables. The first test was about Basic facilities variable obtained 9 items with $\alpha=0.831$. The second was Reputation variable obtained 3 items with $\alpha=0.661$. The third variable was Religious beliefs obtained 3 items with $\alpha=0.691$. The last variable was Behavior of employees obtained 5 items with $\alpha=0.807$. The items deleted from model presented the latent variables Basic facilities and Reputation were (Bfa10; Bfa11; Bfa12; Bfa13; Rep2 and Rep3).

Table 7. The reliability analyses of customer satisfaction variables

\begin{tabular}{cccc}
\hline Code & $\begin{array}{c}\text { Variables of Customer } \\
\text { satisfaction }\end{array}$ & Number of items & Alpha of Cronbach \\
\hline \multirow{2}{*}{ Bfa } & Basic facilities & $(13) ;(12) ;(11) ;(10) ;$ & $0.816 ; 0.822 ; 0.829 ; 0.830 ;$ \\
& Reputation & $(9) ;(4) ;(3)$ & 0.831 \\
\hline Rep & Religious beliefs & $(3)$ & $0.454 ; 0.537 ; 0.661$ \\
\hline Rbe & Behavior of employees & $(5)$ & 0.691 \\
\hline Bem & & & 0.807 \\
\hline
\end{tabular}

\section{c- Reliability test of Loyalty variables}

The reliability test of Loyalty variable allowed to have 5 items with $\alpha=0.777$. The consistency of all items were approved and no items were deleted from research model as shown in Table 8. 
Table 8 . The reliability analyses of loyalty variables

\begin{tabular}{cccc}
\hline Code & $\begin{array}{c}\text { Variables of Customer } \\
\text { satisfaction }\end{array}$ & Number of items & Alpha of Cronbach \\
\hline Lty & Loyalty & $(5)$ & 0.777 \\
\hline
\end{tabular}

\subsubsection{Validity Test}

In examining the validity of a study, it is called internal validity and external validity. The internal validity is the assurance that changes in the dependent variable are caused only by changes in the independent or explanatory variables. The external validity represents the possibilities and limits of extrapolation of the results and conclusions of the research (or study) to the entire area that has been the subject of the investigation, or possibly a broader area. Hence, external validity is the degree of generalization of results, Evrard and al. (2009). Also, in this phase, the internal validity of items is done through normality test with skewness (the asymmetry coefficient) and kurtosis (concentration) coefficients. The results show that all items follow a normal distribution and their values were between $[-3,3]$. The acceptance and validation of items were approved after normality test for SERVQ variables, Customer satisfaction variables and Loyalty variables.

\subsubsection{Factor Analysis}

Factor analysis is used to seek and to identify, from a set of variables, a smaller set of dimensions or factors. In fact, two restrictive conditions are necessary for the analysis; first, the linearity means that the factors are linear combinations of original variables. Second, the independence means that the factors are independent (the correlation coefficients of any two factors are zero), Pett, M.A., and al., (2003). For the purpose of this research and after calculating the Cronbach's alpha was achieved, the researchers proposed to perform a principal component analysis for each variable of service quality, customer satisfaction and loyalty in order to bring about a factor structure. But to achieve this goal, researchers must first examined whether the factors were factorable or not. After that, researchers applied the method of principal component analysis (PCA) to determine the significance of variables in the initial training of new factors. Finally, researchers rotated in the factor space using the "Varimax" method in order to increase the value of the correlation coefficients of variables with the new axes. Also, the table of communalities showed that results were all high, which indicates that the extracted components represent the variables well. The variance explained by the initial solution, extracted components, and rotated components were displayed. The first part of table of Total Variance Explained showed the initial Eigenvalues. The eigenvalues greater than 1 be extracted, hence the first two principal components defined the extracted solution. The second part of the table showed the extracted components. They explain approximately $80 \%$ of the variability in the initial variables, thus researchers considerably reduced the complexity of the items by means of components emerged from analysis, with only a $20 \%$ loss of information.

The rotated component matrix showed the presentation quality of items on the 2 components extracted. The first component was most highly correlated with all items without exclusion. All of items were a better representative, but, because they were less correlated with the other component. Finally, there were one component score variable which representative of all items and replaced the initial variables with near $20 \%$ loss of information. Also, the two components were not linearly correlated with each other. The list of variables and items retained in the model presented in Table 9 below. The validation and approval of measurement scales (items) was achieved and the validation of model needs the second phase of analysis the confirmatory factor analysis with structural equation modelling. 
Table 9. List of variables and items retained in the model (After exploratory factor analysis)

\begin{tabular}{cc}
\hline Latent variables & Items Retained \\
\hline Tan & Tan1; Tan2; Tan3; Tan4; Tan5; Tan6 \\
\hline Rel & Rel3; Re14; Re15; Re16; \\
\hline Res & Res1; Res2; Res3; Res4; Res5; Res6; Res7; Res8; Res9; Res10 \\
\hline Ass & Ass1; Ass2; Ass3; Ass5; Ass7; Ass10; Ass11; \\
\hline Emp & Emp1; Emp2; Emp3; Emp4; Emp5; Emp6 \\
\hline Bfa & Bfa1; Bfa2; Bfa3; Bfa4; Bfa5; Bfa6; Bfa7; Bfa8; Bfa9 \\
\hline Rep & Rep1; Rep4; Rep5 \\
\hline Rbe & Rbe1; Rbe2; Rbe3; \\
\hline Bem & Bem1; Bem2; Bem3; Bem4; Bem5 \\
\hline Lty & Lty1; Lty2; Lty3; Lty4; Lty5
\end{tabular}

\subsubsection{Confirmatory Factor Analysis}

To test the strength and direction of association between the various criteria of the conceptual model, researchers opted for a quantitative methodology through the structural equation modeling (SEM). They were recent developments and the most significant in the studies and marketing research. The SEM can be seen as a combination of both approaches, previously dealt with separately. Firstly, the analysis of latent variables, researchers considered in this step that the observed variables directly reflect, or effect, other variables not directly observable, representing more general concepts that the specific wording of a particular item. Secondly, the structural models designed to represent and to estimate causal relationships between variables; representations commonly used in the form of a set of linear equations, these were the simultaneous equations, network or path analysis. Researchers began with the presentation of two components of causal models: confirmatory factor analysis (measurement model) and the simultaneous equations (structural model), then researchers discussed their integration into the structural equations with latent variables and measurement error. In this section, researchers used Amos software for SEM analysis. For each construct, the measures were purified using total correlations by item-to-item, single measurement model, and CFA (Confirmatory Factor Analysis), Petter, S., and al., (2007).

\subsubsection{The CFA: Case of Conventional Banks}

\subsection{The Reliability and Validity of Constructs}

A confirmatory test of the measurement model was conducted using CFA in the case of conventional banks. As presented in table 10, the first result tested was loadings, the loadings used to examine the convergent validity of constructs, and the value should be more than 0.5 to be accepted. The loadings of measurement constructs exceeded the 0.7. Also, the reliability and validity of constructs needed two statistics indices, the Average Variance Extracted (AVE) for each construct and the Jöreskog's Rhos. The results showed that the AVE of constructs exceeded the 0.5. The (AVE) for the constructs satisfaction was 0.76 , the loyalty was 0.5 , the tangible was 0.63 , the assurance was 0.59 and the empathy was 0.66 . These results approved that the construct variance was further explained by the items that measured by the error. Moreover, the Jöreskog's Rhos of constructs reliability exceeded the threshold 0.7 or 0.8 . For satisfaction it was 0.94 , for loyalty it was 0.83 , for tangible it was 0.91 , for assurance it was 0.91 and for empathy it was 0.92 . In addition, the internal validity of constructs was acceptable and there was a consistency between all measurement constructs. The measurement model gave 5 items presented the variable satisfaction; 5 items presented the variable loyalty; 6 items presented variable tangibles; 7 items presented assurance and 6 items presented variable empathy. Each item was qualified as the best measure of its construct. The convergent validity of our measurement model provided that the construct variance was further explained by the items more that measure by the error. This condition refers to the average variance extracted (AVE) or rho of convergent validity which was greater than 0.5 in this study. The results showed that shared variance between a construct and its measures were more upper than the shared variance between constructs. For the model, the manifest variable was correlated with its own latent variable more than other latent variables. 
Table 10 . The reliability and validity of constructs

\begin{tabular}{|c|c|c|c|c|c|c|c|}
\hline Constructs & Items & Loadings & $\begin{array}{l}\text { Explained } \\
\text { Variance } \\
\text { (AVE) }\end{array}$ & $\begin{array}{c}\text { Number } \\
\text { of } \\
\text { items }\end{array}$ & $\begin{array}{c}\text { Item } \\
\text { Reliabilities } \\
\left(\lambda_{\mathrm{i}}\right)^{2}\end{array}$ & $\begin{array}{c}\delta_{\mathrm{i}} \\
\text { Delta }\end{array}$ & $\begin{array}{c}\text { Jöreskog's } \\
\text { Rhos }\end{array}$ \\
\hline \multirow[t]{5}{*}{ SAT } & LTY & 0.991 & \multirow{5}{*}{$76 \%$} & \multirow{5}{*}{5} & 0.982 & 0.02 & \multirow{5}{*}{0.94} \\
\hline & BFA & 0.792 & & & 0.627 & 0.37 & \\
\hline & REP & 0.831 & & & 0.691 & 0.31 & \\
\hline & RBE & 0.822 & & & 0.676 & 0.32 & \\
\hline & BEM & 0.899 & & & 0.808 & 0.19 & \\
\hline \multirow[t]{5}{*}{ LTY } & Lty1 & 0.719 & \multirow{5}{*}{$50 \%$} & \multirow{5}{*}{5} & 0.517 & 0.48 & \multirow{5}{*}{0.83} \\
\hline & Lty2 & 0.738 & & & 0.545 & 0.46 & \\
\hline & Lty3 & 0.677 & & & 0.458 & 0.54 & \\
\hline & Lty4 & 0.695 & & & 0.483 & 0.52 & \\
\hline & Lty5 & 0.703 & & & 0.494 & 0.51 & \\
\hline \multirow[t]{6}{*}{ TAN } & Tan6 & 0.783 & \multirow{6}{*}{$63 \%$} & \multirow{6}{*}{6} & 0.613 & 0.39 & \multirow{6}{*}{0.91} \\
\hline & Tan5 & 0.723 & & & 0.523 & 0.48 & \\
\hline & Tan4 & 0.818 & & & 0.669 & 0.33 & \\
\hline & Tan3 & 0.832 & & & 0.692 & 0.31 & \\
\hline & Tan2 & 0.826 & & & 0.682 & 0.32 & \\
\hline & Tan1 & 0.792 & & & 0.627 & 0.37 & \\
\hline \multirow[t]{7}{*}{ ASS } & Ass11 & 0.729 & \multirow{7}{*}{$59 \%$} & \multirow{7}{*}{7} & 0.531 & 0.47 & \multirow{7}{*}{0.91} \\
\hline & Ass10 & 0.78 & & & 0.608 & 0.39 & \\
\hline & Ass7 & 0.747 & & & 0.558 & 0.44 & \\
\hline & Ass5 & 0.724 & & & 0.524 & 0.48 & \\
\hline & Ass3 & 0.774 & & & 0.599 & 0.40 & \\
\hline & Ass2 & 0.793 & & & 0.629 & 0.37 & \\
\hline & Ass1 & 0.807 & & & 0.651 & 0.35 & \\
\hline \multirow[t]{6}{*}{ EMP } & Emp6 & 0.765 & \multirow{6}{*}{$66 \%$} & \multirow{6}{*}{6} & 0.585 & 0.41 & \multirow{6}{*}{0.92} \\
\hline & Emp5 & 0.79 & & & 0.624 & 0.38 & \\
\hline & Emp4 & 0.821 & & & 0.674 & 0.33 & \\
\hline & Emp3 & 0.804 & & & 0.646 & 0.35 & \\
\hline & Emp2 & 0.819 & & & 0.671 & 0.33 & \\
\hline & Emp1 & 0.855 & & & 0.731 & 0.27 & \\
\hline
\end{tabular}

\subsection{Analysis of Structural Model}

In this section, the researchers tested the effects between latent constructs to validate or reject hypotheses supported by the analysis model. For further implementation of this research model, the assessment of normality showed that all manifest variables (Sat; Emp; Ass; Tan and Lty) were accepted and follow the normal distribution. The multinormality of all model variables approved by the coefficients (skewness $<3$; kurtosis $<8$ ). The structural adjustment analysis was done to validate the global model in the second step. The computation of degrees of freedom showed the number of distinct sample moments was 406; the number of distinct parameters to be estimated was 62 and the degrees of freedom (406 - 62) was 344. Also, Chi-square $=3242.263$ and the Probability level $=0.000$ as a description results for regression analysis. The estimation of variables by Maximum Likelihood Estimates offered several results. As presented in table 11 concerning regression weights, there was significant relationship between the latent constructs: the first relationship between variables of satisfaction and tangibles which p-value $=0.000<$ 0.005 (statistical significant), the second relationship between variables of satisfaction and loyalty. For the manifest variables and their constructs, the association exists between satisfaction (SAT) and reputation; religious beliefs (RBE); behavior of employees (BEM). The link between these variables was strong and p-value $=0.000<0.005$ (statistical significant). Moreover, the link between loyalty and their manifest variables was approved; there was 4 links for this variable with Lty2; Lty3; Lty4 and Lty5 (the questions are presented successively as: will introduce this bank to others, this bank's services are of high standard, I am happy with the services of this bank, and I will influence others to use this bank). For the variable tangibles as a manifest variable, it exists 5 links with Tan1; Tan2; Tan3; Tan4 and Tan5 (the questions are presented successively as: bank equipped by modern equipment, employees have professional appearance, visually appealing decoration, and employees are well dressed and bank building is perfect). 
Table 11. The regression weights

\begin{tabular}{|c|c|c|c|c|c|c|c|}
\hline & & & Estimate & S.E. & C.R. & $\mathrm{P}$ & Label \\
\hline SAT & $<---$ & TAN & 1.886 & .382 & 4.934 & $* * *$ & par_27 \\
\hline SAT & $<---$ & ASS & 2.975 & 578.975 & .005 & .996 & par_28 \\
\hline SAT & $<---$ & EMP & 2.933 & 612.758 & .005 & .996 & par_29 \\
\hline LTY & $<---$ & SAT & .126 & .005 & 25.853 & $* * *$ & par_8 \\
\hline BFA & $<---$ & SAT & 1.000 & & & & \\
\hline REP & $<---$ & SAT & .365 & .012 & 31.764 & $* * *$ & par 1 \\
\hline RBE & $<---$ & SAT & .356 & .011 & 31.369 & $* * *$ & par_2 \\
\hline BEM & $<---$ & SAT & .615 & .017 & 35.159 & $* * *$ & par_3 \\
\hline Lty1 & $<---$ & LTY & 1.000 & & & & \\
\hline Lty2 & $<---$ & LTY & .973 & .040 & 24.473 & $* * *$ & par_4 \\
\hline Lty3 & $<---$ & LTY & .942 & .042 & 22.356 & $* * *$ & par_5 \\
\hline Lty4 & $<---$ & LTY & .975 & .043 & 22.902 & $* * *$ & par_6 \\
\hline Lty 5 & $<---$ & LTY & .981 & .042 & 23.204 & $* * *$ & par_7 \\
\hline Tan6 & $<---$ & TAN & 1.000 & & & & \\
\hline Tan5 & $<---$ & TAN & .937 & .052 & 17.961 & $* * *$ & par_9 \\
\hline Tan4 & $<---$ & TAN & 1.072 & .052 & 20.602 & $* * *$ & par_10 \\
\hline Tan3 & $<---$ & TAN & 1.059 & .051 & 20.803 & $* * *$ & par_11 \\
\hline $\operatorname{Tan} 2$ & $<---$ & TAN & 1.059 & .051 & 20.575 & $* * *$ & par_12 \\
\hline Tan1 & $<---$ & TAN & .966 & .049 & 19.776 & $* * *$ & par_13 \\
\hline Ass 11 & $<---$ & ASS & .918 & 178.610 & .005 & .996 & par_14 \\
\hline Ass10 & $<---$ & ASS & .951 & 185.033 & .005 & .996 & par_15 \\
\hline Ass 7 & $<---$ & ASS & .925 & 180.094 & .005 & .996 & par_16 \\
\hline Ass 5 & $<---$ & ASS & .895 & 174.165 & .005 & .996 & par_17 \\
\hline Ass 3 & $<---$ & ASS & .967 & 188.167 & .005 & .996 & par_18 \\
\hline Ass2 & $<---$ & ASS & 1.000 & 194.599 & .005 & .996 & par_19 \\
\hline Ass 1 & $<---$ & ASS & 1.000 & 194.535 & .005 & .996 & par_20 \\
\hline Emp6 & $<---$ & EMP & .805 & 168.278 & .005 & .996 & par_21 \\
\hline Emp5 & $<---$ & EMP & .843 & 176.135 & .005 & .996 & par_22 \\
\hline Emp4 & $<---$ & EMP & .876 & 182.942 & .005 & .996 & par_23 \\
\hline Emp3 & $<---$ & EMP & .836 & 174.607 & .005 & .996 & par_24 \\
\hline Emp2 & $<---$ & EMP & .855 & 178.727 & .005 & .996 & par_25 \\
\hline Emp1 & $<---$ & EMP & .888 & 185.526 & .005 & .996 & par_26 \\
\hline
\end{tabular}

In addition, after examined the Standardized Regression Weights (Standardized Loadings), researchers find that the regression coefficients for all variables were between -1 and 1 . The results helped to validate the convergent validity of constructs. In this study all variables satisfy the condition of acceptance except the link between satisfaction and tangibles. Figure 2 shows the causal relationship between exogenous and endogenous variables. The coefficient of paths among latent factors was presented in Figure 2 which describes the exogenous variables represented by tangibles (TAN); Empathy (EMP) and Assurance (ASS) as factors of Service Quality. The endogenous variables were presented by customer satisfaction and loyalty. The customer satisfaction factor represented by behavior of employees (BEM); religious beliefs (RBE); reputation (REP) and basic facilities (BFA). The loyalty factor represented by five variables: Lty1; Lty2; Lty3; Lty4 and Lty5 (the questions are presented successively as: (will continuously use this bank, will introduce this bank to others, this bank's services are of high standard, I am happy with the services of this bank, and I will influence others to use this bank). 


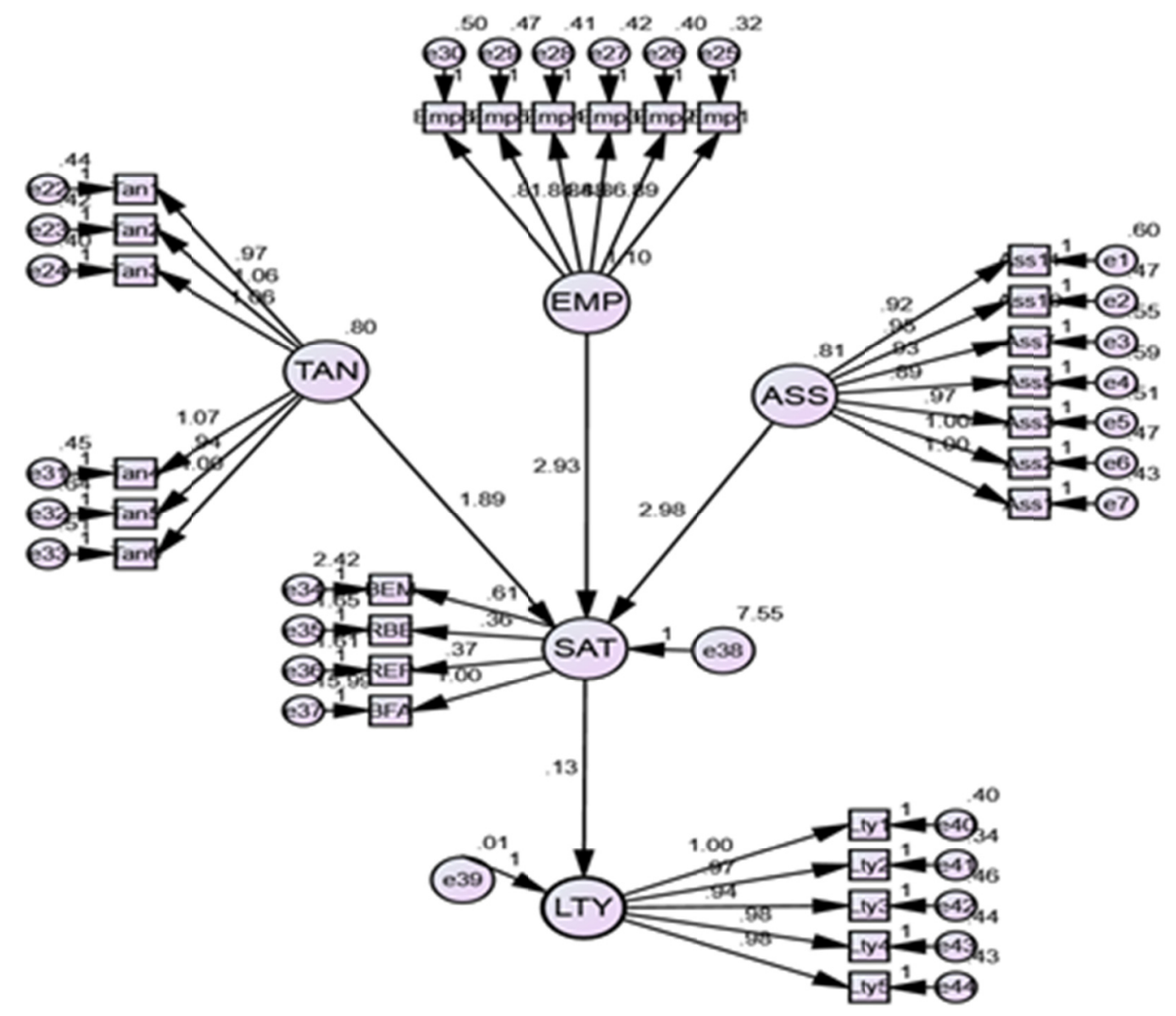

Figure 2. Model fit through a CFA analysis with AMOS software (Case of conventional banks)

The standard errors (S.E) for the loadings variables and path coefficients in the structural model were tested t-values greater than 1.96. The result obtained shows that all of the path coefficients were significant. To validate the global model different adjustment indices were obtained: The absolute indices: measured adjustment of the global model (GFI (goodness of fit indices) - AGFI (Adjusted Goodness of Fit Index) $>0.9$ - RMSEA (Root Mean Square Error of Approximation) $<0.05$ ). The incremental Indices: comparing several models (model tested the null model) (NFI CFI $>0.9$ ). The parsimony indices: which model has a good fit for each estimated coefficient (chi / d.f, ECVI > 0.9); Petter, S. and al., (2007). The Chi-square (X2) = likelihood ratio chi-square of structural model was defined by the CMIN/DF value which equal to 9.425 , this value was more than 7 and it can be accepted in this case, the Goodness of Fit Index (GFI) was equal to 0.745, the Adjusted Goodness of Fit Index (AGFI) was 0.699 and the Parsimonious Goodness of Fit Index (PGFI) was 0.631, the Normed Fit Index (NFI) was 0.787, the Tucker- Lewis Index (TLI) was 0.786, the Comparative Fit Index (CFI) was 0.805, the Parsimonious Normed Fit Index (PNFI) was 0.717, the Root Mean Squared Error of Approximation (RMSEA) was 0.125 which represents the degree to which lack of fit is due to misspecification of the model tested versus being due to sampling error, the Expected cross-validation index (ECVI) was 6.199. All estimated parameters and statistical coefficients were accepted and the global model was significant. The last step of analysis consists to interpret the effects between exogenous and endogenous variables. 
Table 12. The total effects of model variables (Case of conventional banks)

\begin{tabular}{ccccccccccc}
\hline & \multicolumn{2}{c}{ EMP } & \multicolumn{2}{c}{ ASS } & \multicolumn{2}{c}{ TAN } & \multicolumn{2}{c}{ SAT } & \multicolumn{2}{c}{ LTY } \\
\hline Effects & D & I & D & I & D & I & D & I & D & I \\
\hline SAT & 2.933 & 0.000 & 2.975 & 0.000 & 1.886 & 0.000 & 0.000 & 0.000 & 0.000 & 0.000 \\
\hline LTY & 0.000 & 0.369 & 0.000 & 0.374 & 0.000 & 0.237 & 0.126 & 0.000 & 0.000 & 0.000 \\
\hline
\end{tabular}

Notes: D - direct; I - indirect

Table 12 presented the direct and indirect effects of endogenous and exogenous variables, the results showed that exist a direct effect of satisfaction and empathy, assurance and tangibles. For the second factor, the loyalty has an indirect effect within empathy, assurance, tangibles, and a direct effect within customer satisfaction variable.

\subsubsection{The CFA: Case of Islamic Banks}

\subsection{The Reliability and Validity of Constructs}

The same steps were taken in the case of Islamic banks, and the confirmatory test of the measurement model was conducted by using CFA to define individual constructs. As presented in Table 13 of reliability and validity of constructs, the coefficient of reliability Jöreskog's Rhos exceeded the threshold 0.7 for all variables. For the construct reliability (REL) it was 0.79 , for the responsiveness (RES) it was 0.90 , for the satisfaction (SAT) it was 0.79 and for loyalty (LTY) it was 0.82 . The results of Jöreskog's Rhos for the reliability of all constructs were approved. Furthermore, the validity of measurement model was tested with the average variance extracted (AVE), in this study the explained variance for all constructs exceed the threshold of 0.5 . The value of (AVE) for convergent validity of construct it was 0.90 , for the responsiveness it was 0.90 , for satisfaction it was 0.93 and for loyalty it was 0.85 . It is clear that all values were $>0.5$ and the validation of all constructs were statistical approved. The number of items were distributed between constructs as follow: 4 items for reliability, 10 items for responsiveness, 4 items for satisfaction and 5 items for loyalty.

Table 13. The Reliability and validity of constructs (Case of Islamic banks)

\begin{tabular}{|c|c|c|c|c|c|c|c|}
\hline Constructs & Items & Loadings & $\begin{array}{l}\text { Explained } \\
\text { Variance }\end{array}$ & $\begin{array}{l}\text { Number } \\
\text { of items }\end{array}$ & $\begin{array}{c}\text { Item } \\
\text { Reliabilities } \\
\left(\lambda_{i}\right)^{2}\end{array}$ & $\begin{array}{c}\delta_{\mathrm{i}} \\
\text { Delta }\end{array}$ & $\begin{array}{c}\text { Jöreskog's } \\
\text { Rhos }\end{array}$ \\
\hline \multirow[t]{4}{*}{ REL } & Rel3 & 0.948 & \multirow{4}{*}{$90 \%$} & \multirow{4}{*}{4} & 0.899 & 0.10 & \multirow{4}{*}{0.79} \\
\hline & Rel4 & 0.946 & & & 0.895 & 0.11 & \\
\hline & Rel5 & 0.959 & & & 0.920 & 0.08 & \\
\hline & Rel6 & 0.943 & & & 0.889 & 0.11 & \\
\hline \multirow[t]{10}{*}{ RES } & Res1 & 0.948 & \multirow{10}{*}{$90 \%$} & \multirow{10}{*}{10} & 0.899 & 0.10 & \multirow{10}{*}{0.90} \\
\hline & Res2 & 0.954 & & & 0.910 & 0.09 & \\
\hline & Res3 & 0.948 & & & 0.899 & 0.10 & \\
\hline & Res4 & 0.958 & & & 0.918 & 0.08 & \\
\hline & Res5 & 0.945 & & & 0.893 & 0.11 & \\
\hline & Res6 & 0.945 & & & 0.893 & 0.11 & \\
\hline & Res7 & 0.951 & & & 0.904 & 0.10 & \\
\hline & Res8 & 0.958 & & & 0.918 & 0.08 & \\
\hline & Res9 & 0.95 & & & 0.903 & 0.10 & \\
\hline & Res10 & 0.943 & & & 0.889 & 0.11 & \\
\hline \multirow[t]{4}{*}{ SAT } & BFA & 0.951 & \multirow{4}{*}{$93 \%$} & \multirow{4}{*}{4} & 0.904 & 0.10 & \multirow{4}{*}{0.79} \\
\hline & REP & 0.962 & & & 0.925 & 0.07 & \\
\hline & RBE & 0.964 & & & 0.929 & 0.07 & \\
\hline & BEM & 0.977 & & & 0.955 & 0.05 & \\
\hline \multirow[t]{5}{*}{ LTY } & Lty1 & 0.923 & \multirow{5}{*}{$85 \%$} & \multirow{5}{*}{5} & 0.852 & 0.15 & \multirow{5}{*}{0.82} \\
\hline & Lty2 & 0.927 & & & 0.859 & 0.14 & \\
\hline & Lty3 & 0.921 & & & 0.848 & 0.15 & \\
\hline & Lty4 & 0.913 & & & 0.834 & 0.17 & \\
\hline & Lty5 & 0.925 & & & 0.856 & 0.14 & \\
\hline
\end{tabular}


The measurement model helps to design the path analysis which identifying the relationships between exogenous and endogenous variables. In this study, as presented in results of normality assessment, the measurement model follows the assumption of unidimensionality and the multinormality of all variables of model approved by the coefficients (skewness $<3$; kurtosis $<8$ ). The idea was that in a measurement model, an arrow was strained from the manifest variable to the latent variable. Then, after verifying the reliability and validity of constructs, it was necessary to validate the structural model.

\subsection{Analysis of Structural Model}

The analysis of structural paths allowed verifying the cause and effect relationship between constructs. The computation of degrees of freedom offered the number of distinct sample moments was equal to 276 , the number of distinct parameters to be estimated was equal to 49 and degrees of freedom (276 - 49) was equal to 227. The standardized parameter estimated was achieved and the results of analysis presented as Chi-square was equal to 2715.254, the degree of freedom was equal to 227 and Probability level was equal to 0.000 . The analysis of Maximum Likelihood Estimated through the regression weights showed that the existed link between satisfaction and responsiveness equal to the $p$-value which was $<0.005$. The association approved between satisfaction and reliability equal to the p-value which was $<0.005$. Furthermore, third relationship presented between loyalty and satisfaction equal to $\mathrm{p}$-value which was $<0.005$.

Table 14. The regression weights

\begin{tabular}{cccccccc}
\hline & & & Estimate & S.E. & C.R. & P & Label \\
\hline SAT & $<---$ & RES & 5.468 & .403 & 13.559 & $* * *$ & par_20 \\
\hline SAT & $<---$ & REL & 3.295 & .398 & 8.287 & $* * *$ & par_21 \\
\hline LTY & $<---$ & SAT & .114 & .002 & 55.103 & $* * *$ & par_22 \\
\hline Rel3 & $<---$ & REL & 1.000 & & & & \\
\hline Re14 & $<---$ & REL & .998 & .022 & 45.914 & $* * *$ & par_1 \\
\hline Rel5 & $<---$ & REL & 1.001 & .021 & 48.504 & $* * *$ & par_2 \\
\hline Rel6 & $<---$ & REL & .990 & .022 & 45.203 & $* * *$ & par_3 \\
\hline Res1 & $<---$ & RES & 1.000 & & & & \\
\hline Res2 & $<---$ & RES & 1.002 & .021 & 48.585 & $* * *$ & par_4 \\
\hline Res3 & $<---$ & RES & 1.006 & .021 & 47.137 & $* * *$ & par_5 \\
\hline Res4 & $<---$ & RES & 1.009 & .020 & 49.785 & $* * *$ & par_6 \\
\hline Res5 & $<---$ & RES & 1.008 & .022 & 46.459 & $* * *$ & par_7 \\
\hline Res6 & $<---$ & RES & 1.000 & .022 & 46.444 & $* * *$ & par_8 \\
\hline Res7 & $<---$ & RES & 1.002 & .021 & 47.792 & $* * *$ & par_9 \\
\hline Res8 & $<---$ & RES & 1.009 & .020 & 49.660 & $* * *$ & par_10 \\
\hline Res9 & $<---$ & RES & 1.001 & .021 & 47.691 & $* * *$ & par_11 \\
\hline Res10 & $<---$ & RES & .996 & .022 & 45.861 & $* * *$ & par_12 \\
\hline BFA & $<---$ & SAT & 1.000 & & & & \\
\hline REP & $<---$ & SAT & .339 & .005 & 69.473 & $* * *$ & par_13 \\
\hline RBE & $<---$ & SAT & .340 & .005 & 70.562 & $* * *$ & par_14 \\
\hline BEM & $<---$ & SAT & .571 & .007 & 76.269 & $* * *$ & par_15 \\
\hline Lty1 & $<---$ & LTY & 1.000 & & & & \\
\hline Lty2 & $<---$ & LTY & 1.003 & .019 & 51.502 & $* * *$ & par_16 \\
\hline Lty3 & $<---$ & LTY & .995 & .020 & 50.344 & $* * *$ & par_17 \\
\hline Lty4 & $<---$ & LTY & .991 & .020 & 48.810 & $* * *$ & par_18 \\
\hline Lty5 & $<---$ & LTY & .996 & .020 & 51.088 & $* * *$ & par_19 \\
\hline & & & & & & & \\
\hline
\end{tabular}


As presented in Standardized Regression Weights results, the factors loadings were more than 0.5 and the convergent validity of constructs was statistical significant. The t-values were greater than 1.96 . The path coefficients of all constructs were significant (Figure 3).

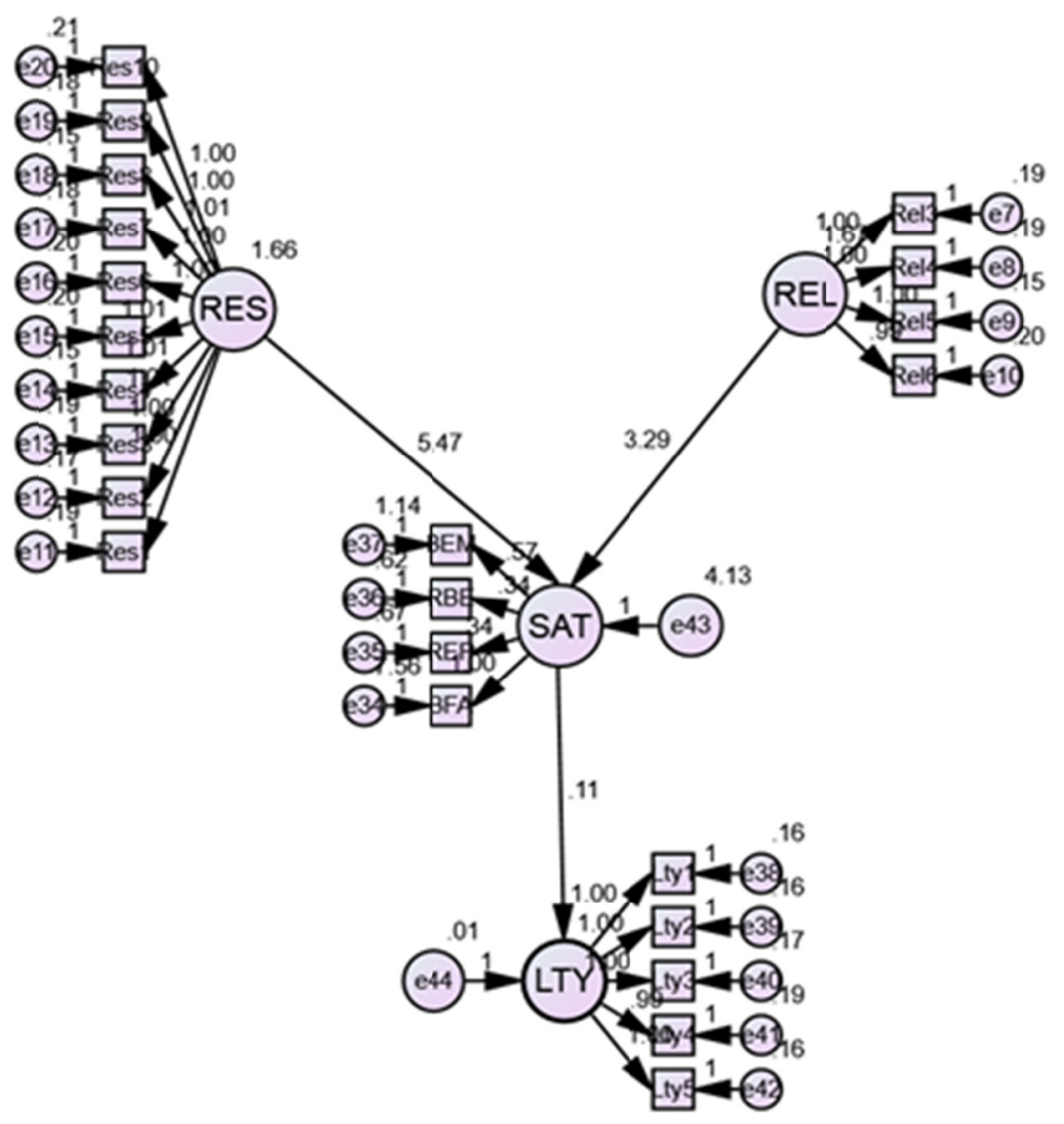

Figure 3. Model fit through a CFA analysis with AMOS software (Case of Islamic bank)

The confirmation of global model needed to examine the structural model validity. In this case, the goodness of fit indices proved that the model has a good fit. The Chi-square $\left(\chi^{2}\right)=$ likelihood ratio chi-square of structural model was defined by the CMIN/DF value which equal to 11.961, this value was more than 7 and could be accepted in this case. The Goodness of Fit Index (GFI) was equal to 0.788; the Adjusted Goodness of Fit Index (AGFI) was 0.742 and the Parsimonious Goodness of Fit Index (PGFI) was 0.648. The Normed Fit Index (NFI) was 0.898. The TuckerLewis (TLI) was 0.894. The Comparative Fit Index (CFI) was 0.905. The Parsimonious Normed Fit Index (PNFI) was 0.805 . The Root Mean Squared Error of Approximation (RMSEA) was 0.147 which represented the degree to which lack of fit was due to misspecification of the model tested versus being due to sampling error. The Expected cross-validation index (ECVI) was 5.571. All estimated parameters and statistical coefficients were accepted and the global model was significant. After goodness of fit validation, the last step of analysis consists to interpret the effects between exogenous and endogenous variables.

Table 15. The total effects of model variables (Case of Islamic banks)

\begin{tabular}{ccccccccc}
\hline & \multicolumn{2}{c}{ RES } & \multicolumn{2}{c}{ REL } & \multicolumn{2}{c}{ SAT } & \multicolumn{2}{c}{ LTY } \\
\hline Effects & D & I & D & I & D & I & D & I \\
\hline SAT & 5.468 & 0.000 & 3.295 & 0.000 & 0.000 & 0.000 & 0.000 & 0.000 \\
\hline LTY & 0.000 & 0.622 & 0.000 & .375 & 0.114 & 0.000 & 0.000 & 0.000 \\
\hline D
\end{tabular}

Notes: $\mathrm{D}$ - direct; I - indirect 
Table 15 presented the direct and indirect effects between endogenous and exogenous variables for the case of Islamic banks, the results indicated that a direct effect between customer satisfaction, responsiveness, and reliability. For the second factor, the loyalty had indirect effect within responsiveness and reliability, and direct effect within customer satisfaction variable.

\section{Discussion of Research Findings}

There was a consistency with the literature and the validation of hypotheses which was approved in some cases. For the hypothesis 1 , the Islamic banks provided services quality to customers better than conventional banks, this assumption was not supported and that supported the research of Abedniya, A., \& Zaeim, M.N., (2011); Islam. S., and Borak Ali, Md., (2011); Blanchard and Galloway, (1994). These authors declared that the lack of experience of employees of Islamic banks and they are not able to carry out operations and services of Islamic Finance banks conversely to conventional banks. For the hypothesis 2 , the loyalty to the service quality of Islamic banks has greater efficiency than conventional counterparts; this hypothesis was supported by the results found by Ehigie, (2006); Abedniya, A., \& Zaeim, M.N., (2011); Ravichandran and al., (2010); Zeitun, R. (2012), that the customer satisfaction and service quality are the significant predictors of customer loyalty in the case of Islamic banks. The loyalty is more important in Islamic banks than in conventional banks because the trust and confidence of customers on IB operations more than CB. This is due to religious beliefs; reputation of banks and behavior of banks employees. Similarly, findings revealed that hypothesis 3 , (the religious beliefs play a major role on customer satisfaction in Islamic banks than conventional banks), this assumption was confirmed, and when the researchers make comparison between IB and CB, three dimensions emerged from the following factor customer: satisfaction the reputation of banks, religious beliefs, and behavior of employees. These dimensions were common in IB and CB, but the degree of correlation with IB was more than was in $\mathrm{CB}$, that was why the role of religious beliefs in IB is major to define the tendencies of customers. Moreover, "the system based on "Chariaa requirements" and the confidence gives to Islamic banks by many financial institutions revealed the importance of religious beliefs and its impact on customer satisfaction", Jham \& Khan (2008); Nazal, A.I., (2015); Methlie, L., and Nysveen, H., (1999). Hypothesis 4 indicated that the behavior of employees had a positive and greater impact on customer satisfaction in Islamic banks than conventional banks. This assumption was not supported, this result resembles to research of Islam. S., and Borak Ali, Md., (2011) who approved that the role of employees and their behavior include employees' knowledge, courtesy and ability to convey trust and confidence to the clients and stakeholders and they confirm the highest of impact on conventional banks more than in Islamic banks. Therefore, Hypothesis 5 described that the basic facilities have a positive and greater impact on customer satisfaction in Islamic banks than conventional banks. This assumption was not supported and it was confirmed by the authors Lee and al., (2000), who reveal that the basic facilities have a positive and greater impact on customer satisfaction in conventional banks than in Islamic banks. Hypothesis 6 defined that the reputation had a positive and greater impact on customer satisfaction in Islamic banks than conventional banks. This assumption was not supported and Abedniya, A., \& Zaeim, M.N., (2011), had written about this by saying: "may lead negative reputation to the loss of funding sources or could lead customers to convert to banks compete, and this impression is created as a result of the actions carried out by the manager or the bank staff or as a result of lack of customers quality service and the desired speed ". They approve that the reputation in CB had a greater impact on customer satisfaction more than in IB. Hypothesis 7 described that there were positive and greater relationships between service quality and customer satisfaction regarding Islamic banks than conventional banks. This assumption was partially approved because the results of this research offer that existed two types of relationships in both cases IB and CB. The first case about CB gave that the relationship was between customer satisfaction and empathy, assurance and tangibles. Conversely, for the second case of IB the relationship is between customer satisfaction, responsiveness, and reliability. Each case had a special result and confirmation for hypothesis. The finding did not correspond with some previous studies but there were some researchers who study this relationship like the authors Fornell et al, (1996); Ahmad and Hasan (2007), Jham \& Khan (2008); Lee et al. (2000); Islam. S., and Borak Ali, Md., (2011). They confirmed that the "customer satisfaction" is recognized as being highly associated with two dimensions, the first dimension is perceived quality and the second is perceived value. Specifically, there has been a convergence between the feeling of satisfaction and the service offered by bank. The customer satisfaction and service quality are the significant predictors of customer loyalty; Ehigie, (2006).

\section{Conclusions, Limitations and Future Research Scope}

The findings showed that the mediating role of customer satisfaction between service quality and loyalty was major in same cases of CB or IB. However the difference was perceived in the nature of determinants which presented each factor: service quality and customer satisfaction or loyalty. Then, the comparison between results obtained in case of Islamic and conventional banks indicated that the service quality had impact on loyalty through customer satisfaction. 
The effect of this relationship is differed between the variables which affect the model directly or indirectly. In case of conventional banks, the service quality had a positive indirect impact with loyalty through customer satisfaction. For more detail, the nature of this relationship reveal that exist a direct link between empathy; assurance and tangibles as a determinant of service quality and customer satisfaction. The customer satisfaction was defined by reputation; religious beliefs and behavior of employees. In conventional banks, the customer motivated in his dealing with bank by the reputation of banks; the religious beliefs and behavior of employees at the moment of offering the service to customer. The effect of service quality on loyalty was indirect but it was observable through the customer satisfaction as a mediating variable. Then, the loyalty and customer satisfaction have a direct association and the role of service quality was fundamental to ensure the customer satisfaction and loyalty as a final step. Conversely, in case of Islamic banks the results shown that direct effect exist between customer satisfaction, responsiveness, and reliability as determinant of service quality factor. The loyalty revealed indirect effect within responsiveness and reliability. For the link with satisfaction, there was direct and positive relationship. The customer satisfaction presented three dimensions: reputation, religious beliefs, and behavior of employees. In general, the relationship between service quality and loyalty approved through customer satisfaction as a mediator variable. Indeed, the composite nature of service quality and customer satisfaction to ensure customer loyalty as a research topic reveals limitations in this study, the role of customer satisfaction as mediating variable is not usually valid for all studies, there was other variables that could be tested to define the relationship between service quality and loyalty as strategic decision making process or knowledge management process. Other limits for the research were about the choice of respondents and the data availability. The majority of respondents belong to the category of employees, they presented $60 \%$ of the sample, but in reality, the important customers of banks in KSA were traders who presented in our sample as professionals with $15 \%$, and the rate of females were $26 \%$ who presented $1 / 4$ of our sample, therefore it was not easy to determine pertinent sample characteristics. The findings could be changed if another sector were used. Many variables could be introduced in research model could improve the significance quality of findings and gave other contribution for the study as the process approach, the system approach to management, the leadership, the enhancement of managers, the involvement and commitment of employees, customer focus, continual improvement, factual approach to decision making and Mutually beneficial supplier relationships. These eight principles of quality management (ISO 9001v2008) were also useful resources for the researchers and professionals looking to improve the service quality and quality management program for both Islamic and Conventional banks. To conclude, the researchers may use these principles to test other model with other variables as extend of this study for banking and/or manufacturing sectors.

\section{Acknowledgements}

The authors appreciate the role of Umm al Qura University through the Institute of Manuscripts and Revival of Islamic Heritage (IMRIH) for the financing and useful helps to achieve this research project.

\section{References}

Abedniya, A., \& Zaeim, M.N. (2011). Measuring the perceive service Quality in the Islamic Banking System in Malaysia. International Journal of Business and Social Science, 2(13), 122-135.

Ahmad, A.U.F., \& Hasan, M.K. (2007). Regulations and Performance of Islamic Banking in Bangladesh", Thunderbird International Business Review, 49(2), 251-277. http://dx.doi.org/10.1002/tie.20142

Blanchard, R.F., \& Galloway, R.L. (1994). Quality in Retail Banking. International Journal of Service Industry Management, 5(4), 5-23. http://dx.doi.org/10.1108/09564239410068670

Cronin, J.J., Jr., \& Taylor, S.A., (1992). Measuring service quality: A reexamination and extension. Journal of marketing, 56(3), 55-68. http://dx.doi.org/10.2307/1252296

Dietrich, A., \& Wanzenried, G. (2011). Determinants of bank profitability before and during the crisis: Evidence from Switzerland. International Financial Markets, Institutions and Money, 21, 307-327. http://dx.doi.org/10.1016/j.intfin.2010.11.002.

Ehigie, B.O. (2006). Correlates of Customer Loyalty to Their Bank: A Case Study in Nigeria. International Journal of Bank Marketing, 24, 494-508. http://dx.doi.org/10.1108/02652320610712102

Evrard, Y., Bernard, P., \& Elyette, R. (2009). Market: Fondements et méthodes des recherches en marketing (4ième éd.). Les Editions Dunod, Paris.

Fornell, C., Johnston, M. D. Anderson, E., Cha, J., \& Bryant, B. E. (1996). The American Customer Satisfaction Index: Nature, Purpose, and Findings. Journal of Marketing, 60(4), 7-18. http://dx.doi.org/10.2307/1251898 
Harrison-Walker, L. Jean., (2001). The measurement of word of mouth communication and an investigation of service quality and customer commitment as potential antecedents. Journal of Service Research, 4, 60-75. http://dx.doi.org/10.1177/109467050141006.

Idris, A.R, Asari, A. H., Taufik, N. A. A., Salim, N. J., Mustaffa, R., \& Jusoff, K. (2011). Determinant of Islamic Banking Institutions' Profitability in Malaysia. World Applied Sciences Journal, 12(12), 1-7.

Islam. S., \& Borak Ali, Md., (2011). Measuring Service Quality of Banks: An Empirical Study. Research Journal of Finance and Accounting, 2(4), 74-86.

Jham, V., \& Khan, K.M. (2008). Determinants of Performance in Retail Banking: Perspective of Customer Satisfaction and Relationship Marketing. Singapore Management Review, 30(2), 35-45.

Kamaruddin, B. H., Safa, M.S., \& Mohd, R. (2008). Assessing production efficiency of Islamic banks and conventional banks in Malysia. MPRA, International Journal of Business and Management Research, 1(1), 31-48.

Karim, M., \& Chan, S.G. (2007). Off-Balance Sheet Activities and Performance of Commercial Banks in Malaysia. ICFAI Journal of Financial Economics, 5(4), 67-80.

Lee, H., Lee, Y., \& Yoo, D. (2000). The Determinants of Perceived Service Quality and its Relationship with Satisfaction. Journal of Service Marketing, 14(3), 217-231. http://dx.doi.org/10.1108/08876040010327220

Masood, O., \& Muhammad, A. (2012). Bank-specific and macroeconomic profitability determinants of Islamic banks: The case of different countries. Qualitative Research in Financial Markets, 4(2/3), 255-268. http://dx.doi.org/10.1108/17554171211252565

Methlie, L. B., \& Nysveen, H. (1999). Loyalty of on-line Bank Customers. Journal of Information Technology, 14(4), 375-386. http://dx.doi.org/10.1080/026839699344485

Nazal, A.I. (2015). Financial Analysis Problems in Specialized Islamic Bank. International Review of Management and Business Research, 4(2), 414-421.

Olson, D., \& Zoubi, T.A. (2011). Efficiency and bank profitability in MENA countries. Emerging Markets Review, 12(2), 94-110. http://dx.doi.org/10.1016/j.ememar.2011.02.003

Parasuraman, A., Zeithaml, V.A., \& Berry, L.L. (1985). A Conceptual Model of Service Quality and its Implications for Future Research. Journal of Marketing, 49(4), 41-50. http://dx.doi.org/10.2307/1251430

Parasuraman, A., Zeithaml, V.A., \& Berry, L.L. (1994). Alternative Scale for Measuring Service Quality: A Comparative Assessment Based on Psychometric and Diagnostic Criteria. Journal of Retailing, 70(3), 201-230. http://dx.doi.org/10.1016/0022-4359(94)90033-7

Parasuraman, A., Zeithaml, V.A., \& Berry, L.L. (1988). SERVQUAL: a multiple item scale for measuring consumer perceptions of service quality. Journal of Retailing, 64(1), 12-40.

Pett, M. A., Lackey, N. R., \& Sullivan, J. J. (2003). Making sense of factor analysis: The use of factor analysis for instrument development in health care research. Thousand Oaks, CA: Sage Publications.

Petter, S., Straub, D., \& Rai, A. (2007). Specifying Formative Constructs In Information Systems Research. MIS Quarterly, 31(4), 623-656.

Ponce, T. A. (2012). What determines the profitability of banks? Evidence from Spain. Accounting and Finance, 53(2), 561-86. http://dx.doi.org/10.1111/j.1467-629X.2011.00466.x

Raissi. N., \& Chaher. M. (2014). 'The relationship between ISO certification and companies performance: Case of Certified Tunisian Companies', Journal of Business and Management Research, 6(1), 131-150.

Ravichandran, K., Tamil Man, B., Arun Kumar, S., \& Prabhakaran, S. (2010). Influence of Service Quality on Customer Satisfaction Application of Servqual Model. International Journal of Business and Management, 5(4), 117-124.

Schaupp, L., \& Bélanger, F. (2005). A Conjoint Analysis of Online Consumer Satisfaction. Journal of Electronic Commerce Research, 6(2), 95-111.

Shapiro, S. E., Lasarev, M. R., \& McCauley, L. (2002). Factor analysis of Gulf War illness: What does it add to our understanding of possible health effects of deployment. American Journal of Epidemiology, 156(6), 578-585. http://dx.doi.org/10.1093/aje/kwf087 
Sufian, F., \&Abdul Majid, M.Z. (2007). Singapore banking efficiency and its relation to stock returns: A DEA window analysis approach. International Journal of Business Studies, 15(1), 83-106.

Sufian. F., \& Majid, M.Z.A. (2011). The Nexus between Economic Freedom and Islamic Bank Performance: Empirical Evidence from the MENA Banking Sectors. 8th International Conference on Islamic Economics and Finance, pp. 1-24.

Tsoukatos, E., \& Mastrojianni, E., (2010). Key determinants of service quality in retail banking. EuroMed Journal of Business, 5(1), 85-100. http://dx.doi.org/10.1108/14502191011043170

Viverita, Brown, K., \& Skully, M., (2007). Efficiency analysis of Islamic banks in Africa, Asia and Middle East, Review of Islamic Economics, 11(2), 5-16.

Yavas, U., Benkenstein, M., \& Stuhldreier, U. (2004). Relationships between service quality and behavioral outcomes: A study of private bank customers in Germany. International Journal of Bank Marketing, 22(2), 144-157. http://dx.doi.org/10.1108/02652320410521737

Zeitun, R. (2012). Determinants of Islamic and Conventional Banks Performance in GCC Countries Using Panel Data Analysis. Global Economy and Finance Journal, 5(1), 53-72. 